\title{
Automation of Work Distribution in the Management of Mining Enterprises
}

\author{
Fares Nadim Abou-Abed ${ }^{1}$ \\ ${ }^{1}$ Tver State Technical University, A. Nikitin Street, 22, 170026, Tver, Russia
}

\begin{abstract}
Currently, mining industry enterprises are becoming leaders in labor automation. This process affects both extraction of minerals and management. As a result, the scientific organization of automation of management plays a special role of increasing labor productivity, in which the distribution of work tasks occupies a special place. The article discusses one of the stages of the production program of industrial enterprises, distribution of work on the existing departments and contractors. The article presents the basic criteria of the assignment of jobs. It proposed a software system that allows you to automate and optimize the process. As a criterion for optimization relies total cost of doing all the work.
\end{abstract}

\section{Introduction}

For industrial companies operating in a market economy, one of the most important tasks is the task of effective production management. At the same time, the formation of a production program, in addition to scheduling, the development of production plans, the supply of raw materials, the provision of the required amount of various resources and organizational and control activities, inevitably includes the distribution of work across the available production facilities [1]. Optimization of the distribution of work significantly reduces financial costs and allows achieving a positive economic effect [2].

\section{Method used}

Work distribution model.

In general, the distribution of work between production units is controlled based on such basic criteria as [3-5]:

- availability of resources necessary to perform the work;

- quantitative and qualitative levels of labor resources;

- time constraints;

- financial costs for work performance;

- uniformity of loading of available production facilities [6].

Some of these criteria are strict - for example, the availability of the required amount of raw materials, labor resources, time frames, but financial costs can vary in a certain range, because the final cost of the work depends on many factors. It is for this indicator that it is advisable to optimize the distribution of orders. 
The formalization of the presented criteria and the allocation of the objective function of the problem made it possible to design its model and carry out the algorithmization of one of the possible solutions [7-8].

The assessment of the contractor for quality (availability of a resource base, equipment, qualified specialists) is carried out on the basis of expert assessments and special reports; time constraints, the workload of the segments of the enterprise is determined based on the volumetric scheduling, the financial component - on the basis of the concluded agreements and contracts [9].

As an optimization criterion, the total cost of all work performed by the production units of the enterprise or its counterparties is used.

\section{Results and Discussion}

The optimization planning system developed for the presented distribution model, on the basis of which the solution algorithm is implemented, is characterized by the following parameters. Input characteristics [10]:

- many works characterized by parameters:

- the allocated amount of funds for implementation;

- directive execution time;

- assessment of the amount of resources required for the implementation;

- assessment of the required labor resources;

- many production units and contractors available to the enterprise:

- minimum financing of the unit;

- the maximum amount of funds allocated to the unit.

- characteristics reflecting the capabilities of departments to perform a particular type of work:

- the amount of required financial resources;

- the time required to complete the work;

- available resources;

- available labor resources [11].

At the end of the work of the algorithm for finding the optimal solution - the distribution of work by performer - the planning system displays the following results:

- all possible types of work that can be performed by each of the departments without violating the qualitative and quantitative requirements

- a variant of the distribution of work by performer, in which the total cost of performing all work is minimal [12].

The general structural diagram of the optimization planning system is shown in Figure 1. Work distribution optimization system.

When constructing and decomposing the structure of an automated system, a simplified MVC concept, Model-View, is used, where the View also acts as a controller that processes user actions and changes the model and view accordingly.

The subsystem of internal data presentation is used as a model describing the internal structure.

The interface subsystem acts as a presentation.

Information exchange between the components of the system is implemented as follows: 
Table 1. Information interaction of software modules.

\begin{tabular}{|c|c|c|c|c|}
\hline & $\begin{array}{c}\text { Interface } \\
\text { subsystem }\end{array}$ & $\begin{array}{c}\text { Subsystem } \\
\text { for storing } \\
\text { and loading } \\
\text { data }\end{array}$ & $\begin{array}{c}\text { Subsystem for } \\
\text { internal data } \\
\text { presentation }\end{array}$ & $\begin{array}{c}\text { Subsystem for } \\
\text { analysis and } \\
\text { search for } \\
\text { solutions }\end{array}$ \\
\hline $\begin{array}{c}\text { Interface } \\
\text { subsystem }\end{array}$ & $\mathrm{X}$ & $\mathrm{X}$ & $\mathrm{X}$ & $\mathrm{X}$ \\
\hline $\begin{array}{c}\text { Data } \\
\text { storage and } \\
\text { loading } \\
\text { subsystem }\end{array}$ & $\mathrm{X}$ & $\mathrm{X}$ & $\mathrm{X}$ & \\
\hline $\begin{array}{c}\text { Internal } \\
\text { data } \\
\text { presentation } \\
\text { subsystem }\end{array}$ & $\mathrm{X}$ & & $\mathrm{X}$ & \\
\hline $\begin{array}{c}\text { Subsystem } \\
\text { for analysis } \\
\text { and search } \\
\text { for } \\
\text { solutions }\end{array}$ & & & & \\
\hline
\end{tabular}

Thus, the developed software tool has a modular architecture, the main elements of which are shown in the diagram.

In accordance with the object-oriented approach, all subsystems, modules and entities that reflect the concepts of the domain are represented as a collection of objects, each of which is an instance of a certain class, and the classes form an inheritance hierarchy.

Carrying out experimental calculations (Checking the software model).

While the reliability and adequacy of the model, as well as the correctness of the algorithmization of its research follows from the mathematical validity of the approaches and methods used, their implementation needs to be verified.

A reliable way to check the correctness of the model, its software implementation and research algorithms is to check on the edge values of the input data and on the amount of data that allows you to control the results obtained explicitly.

For the described problem, these will be two cases:

1. Iintroducing constraints under which a solution cannot be found:

- insufficient number or absence of bids from contractors for one / several works;

- for one / several works there are no applications of candidates that meet the financial, temporary or quality requirements of the customer;

- it is impossible to distribute the work without violating the financial restrictions on the allocated funds for one / several executing organizations; 


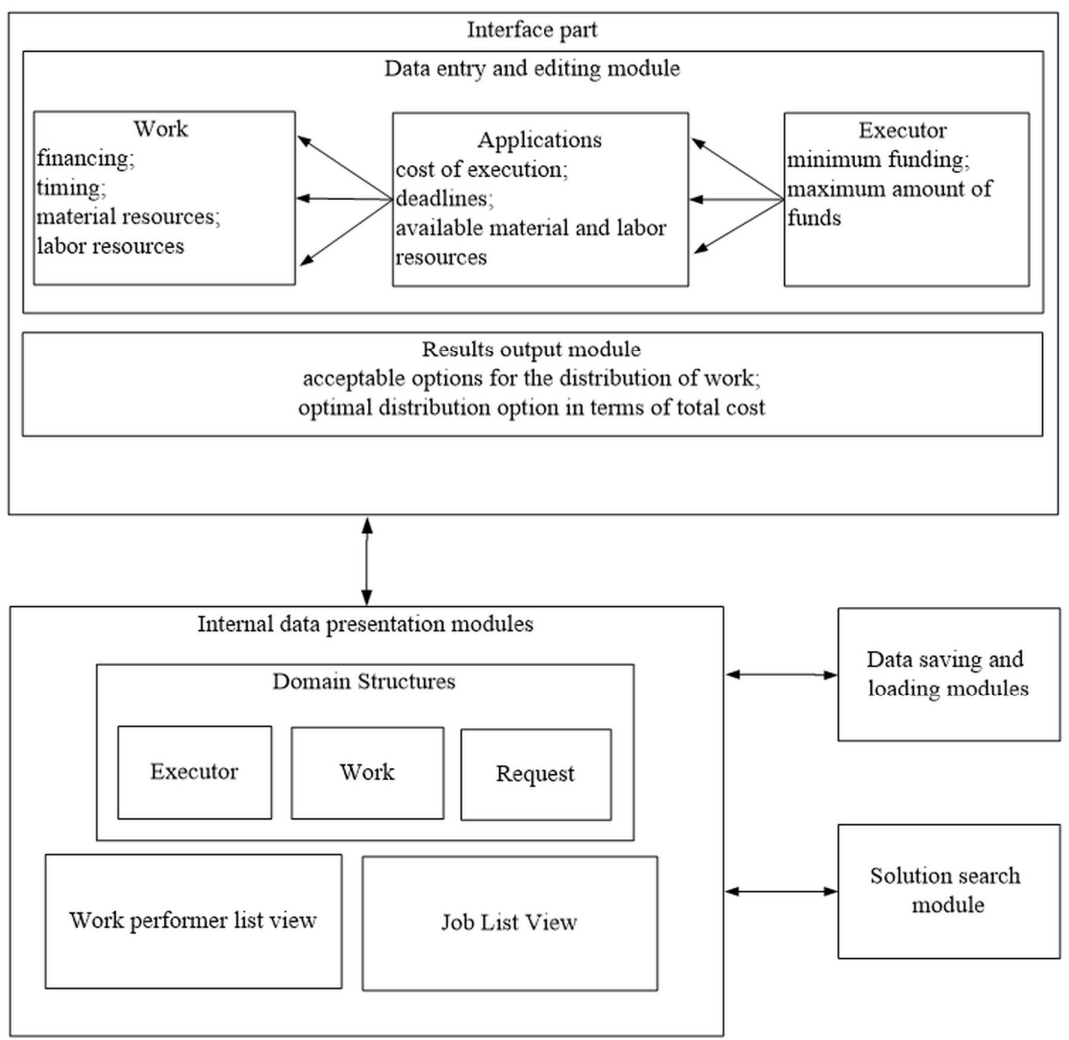

Fig. 1. Structure of the work distribution optimization system.

2. All applications satisfy all the customer's requirements, there are no restrictions on the allocated funds and the selection should be made based only on the proposed costs and the timing of the work.

For the first case, respectively, the result of the work should be a message about the absence of a solution, in which all the specified requirements are met.

For the second, a solution must be found in which among all submitted applications for a specific type of work, the application with the lowest proposed cost is selected.

It is advisable to check the model using the developed software application, which will immediately check not only the adequacy of the formalized model, but also the operation of the software.

For verification, the following possible options were considered:

- in all applications of applicants for the same specific work, data were entered that did not meet the requirements of the customer: the project budget was exceeded, the target time was longer than the designated time, the calendar dates differ from the established ones, or applications were entered from contractors who do not have sufficient resources or qualifications for its implementation;

- financial frameworks have been established for one or several performers in such a way that it is impossible to appoint them to perform work without violating the lower or upper limit of the contractor's financing volume, and there are no other applicants for the performance of these works.

The result of starting the process of finding optimal solutions was, as expected, a message about the absence of solution options. 
When checking the second type, for all applicants from the introduced list, restrictions on the total budget of the work performed were removed, i.e. the minimum amount of funding was set to 0 , and the maximum allowed was absent.

In the course of searching for a solution under the given conditions, it was revealed that for each job, an application with the smallest value of the objective function (proposed cost and terms of performance of the work) is selected from the existing ones, which confirms the correctness of the operation and software implementation of the algorithm.

For a comparative assessment, the minimum total cost of completing a package of projects in the case of priority price optimization and the total terms of work in the case of a temporary priority were determined, i.e. the best variant of the distribution obtained during the operation of the algorithm. Valid options were assessed based on the average values of all found.

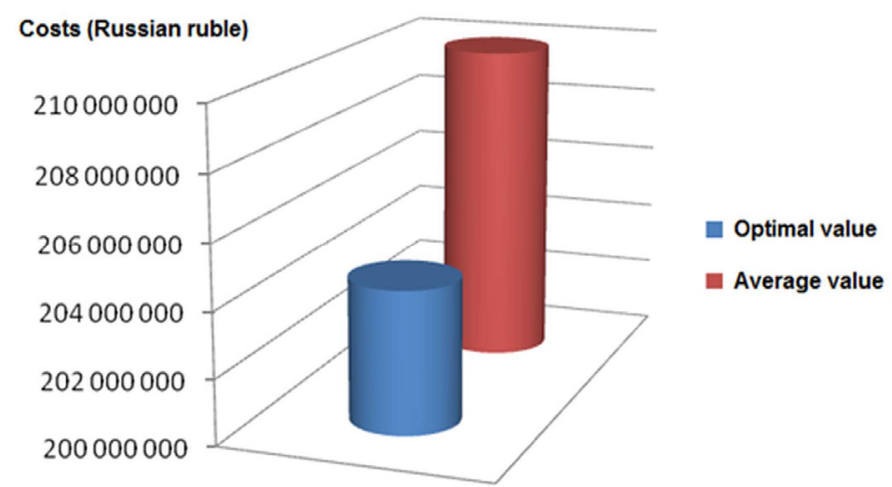

Fig. 2. Results of cost optimization.

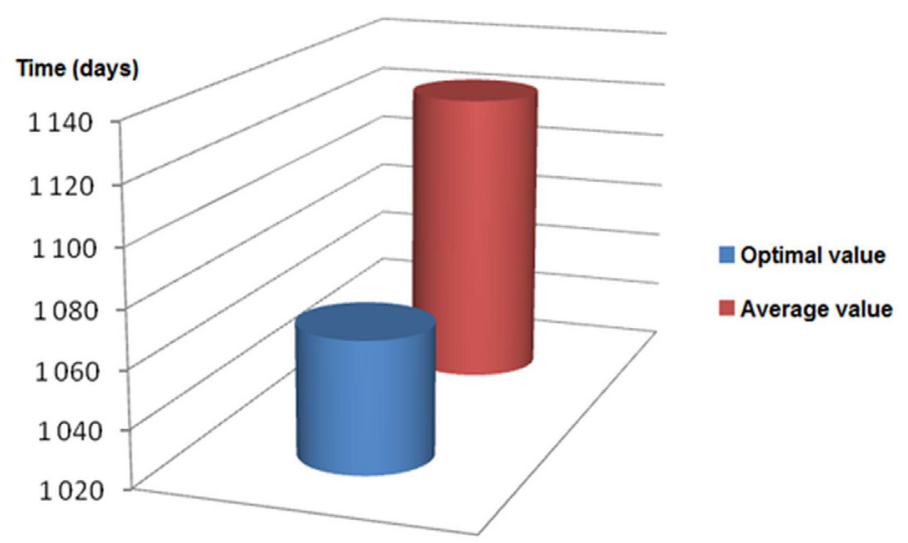

Fig. 3. Results of cost optimization.

\section{Conclusions}

Today, the automation of production management and planning processes at industrial enterprises is an essential requirement for an effective organization policy. The proposed system for the optimization of the distribution of work is based on the basic characteristics that are applicable in most production areas and can be used at one of the stages of planning the activities of the enterprise. 


\section{References}

1. M. Yazevich, O. Kalinina, E3S Web Conf. 134, 03004 (2019)

2. Zhironkin, A. Selyukov, M. Gasanov, Energies, 13(13), 3305 (2020)

3. R. Kozel, S. Vilamova, P. Baranek, V. Friedrich, Z. Hajduova, M. Behun, Acta Montanistica Slovaca, 22(4), 439-447 (2017)

4. M. Hakelová, A. Csikósová, M. Antošová, Acta Montanistica Slovaca, 18(2), 85-90 (2013)

5. P. Madzík, A. Daňková, J. Piteková, V. Ferencz, Acta Montanistica Slovaca, 21(1), 6775 (2016)

6. F. N. Abu-Abed, L. G. Naumova, J. Min. Geot. Eng. 3:6, 21-35 (2019) DOI: 10.26730/2618-7434-2019-3-21-35

7. D.B Shatko, V.V. Kryukova, Economics and Innovation Management, 4, 86-97 (2019) DOI: 10.26730/2587-5574-2019-4-86-97

8. A.G. Pimonov, E.A. Glebova, T.V. Sarapulova, V.V. Glebov, Economics and Innovation Management, 3, 52-65 (2017) DOI: 10.26730/2587-5574-2017-3-52-65

9. F. Abu-Abed, E3S Web Conf. 105, 03006 (2019)

10. F. Abu-Abed, E3S Web Conf. 105, 03017 (2019)

11. F. Abu-Abed, N. Borisov, E3S Web Conf. 21, 01019 (2017)

12. Fares Nadim Abou-Abed, E3S Web Conf. 174, 04015 (2020) 